\title{
Health-related claims on food labels in Australia: understanding environmental health officers' roles and implications for policy
}

\author{
Deanne Condon-Paoloni ${ }^{*}$, Heather R Yeatman and Elizabeth Grigonis-Deane \\ School of Health Sciences, University of Wollongong, Wollongong, NSW 2522, Australia
}

Submitted 5 April 2013: Final revision received 23 September 2013: Accepted 15 October 2013: First published online 20 November 2013

\begin{abstract}
Objective: Health and related claims on food labels can support consumer education initiatives that encourage purchase of healthier foods. A new food Standard on Nutrition, Health and Related Claims became law in January 2013. Implementation will need careful monitoring and enforcement to ensure that claims are truthful and have meaning. The current study explored factors that may impact on environmental health officers' food labelling policy enforcement practices.

Design: The study used a mixed-methods approach, using two previously validated quantitative questionnaire instruments that provided measures of the level of control that the officers exercised over their work, as well as qualitative, semi-structured, in-depth interviews.

Setting: Local government; Australia.

Subjects: Thirty-seven officers in three Australian states participated in semi-structured in-depth interviews, as well as completing the quantitative questionnaires. Senior and junior officers, including field officers, participated in the study.

Results: The officers reported a high level of autonomy and control of their work, but also a heavy workload, dominated by concerns for public health and food safety, with limited time for monitoring food labels. Compliance of labels with proposed health claims regulations was not considered a priority. Lipsky's theory of street-level bureaucracy was used to enhance understanding of officers' work practices.

Conclusions: Competing priorities affect environmental health officers' monitoring and enforcement of regulations. Understanding officers' work practices and their perceptions of enforcement is important to increase effectiveness of policy implementation and hence its capacity to augment education initiatives to optimize health benefits.
\end{abstract}

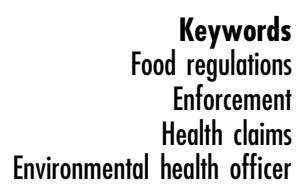

Keywords

Enforcement

Health claims

Environmental health officer
Many countries, including Australia, have responded to both consumer and industry demand for clear regulation concerning health and related claims on food labels ${ }^{(1-3)}$ as well as concerns about high levels of non-compliance with existing regulations ${ }^{(4)}$. A new food Standard on Nutrition, Health and Related Claims became law in Australia and New Zealand in January $2013^{(5)}$. This new Standard sets the rules for the nutrition content and health claims that can be used on food labels and in food advertisements. However, food labels may also carry a wide range of statements that are not covered by this new Standard but shoppers still may perceive them as related to health (e.g. 'wholegrain'). Further, some claims on food labels are regulated under other legislation or processes and different rules will apply, adding more complexity to the issue.

A supportive food policy environment is essential to facilitate healthy choices. The appropriate use and placement of claims on food labels can be a useful tool for consumers trying to buy healthier foods. Up to $85 \%$ of people, especially those with special needs, report that they read nutrition information panels and other health-related information on the food label ${ }^{(6-12)}$, although observational studies suggest a much lower proportion $^{(13)}$. Recent research has shown that a high proportion of products currently carry health claims ${ }^{(14)}$ and some of these may confuse or mislead consumers ${ }^{(15)}$. Consumers need to be able to trust that label information meets identifiable standards ${ }^{(16)}$. Effective implementation of health claims regulations will require appropriate monitoring and enforcement of the regulations.

In Australia, environmental health officers have responsibility for monitoring and enforcing the laws and regulations governing public health including food safety ${ }^{(17)}$. Research has found that officers are comfortable with their role and knowledge regulating food safety ${ }^{(18)}$. 
However, officers may find the responsibility for monitoring the new Standard challenging, citing concerns such as workload, the priority of health claim labelling relative to food safety and hygiene, and the need for consumer education $^{(8)}$. Lack of qualified personnel is also an issue ${ }^{(19)}$.

The impact of the changes in food labelling standards on the role of environmental health officers in Australia has not previously been reported. The factors influencing their decisions about prioritization of workload are unknown. The current mixed-methods study explored the roles of environmental health officers in relation to food regulations and their decision-making practice in setting task priorities. Lipsky's model of street-level bureaucracy ${ }^{(20)}$ was used as a framework to help understand how the new Standard may be delivered to the public.

\section{Lipsky's model: public servants as 'street-level bureaucrats'}

Lipsky ${ }^{(20)}$ proposed that public servants have a direct influence in shaping policy. He defined the term 'streetlevel bureaucrats' as those employees working in public service with a high degree of autonomy and a high degree of interaction with the community, for example social welfare workers or police. These workers used their professional expertise to address the needs of their clients; they enforced sometimes vague policy which was open to interpretation; they enjoyed a high degree of discretion in decision making; they were not closely observed in the workplace; and they developed coping techniques to manage the constraints of the workplace.

In Lipsky's model, street-level bureaucrats had a heavy workload, the demand for their services was often unpredictable and they directly interacted with clients. They also experienced organizational constraints including limited resources, conflict between client needs and organizational goals, and supervision by managers who themselves experienced conflicting goals and organization objectives. Lipsky argued that street-level bureaucrats developed mechanisms to lessen these tensions through selective or non-enforcement of regulations and less than optimal delivery of policy.

In the present paper, we argue that environmental health officers can be seen as street-level bureaucrats, accountable to both their superiors (employers) and their clients and the public, within the context of values, morals and expectations ${ }^{(21)}$. Tensions arising from competing accountabilities may lead to their use of discretion in prioritizing their workload duties and in enforcing regulations. Such use of discretion in relation to their role in regulating health claims may result in incomplete enforcement and hence variable veracity and promulgation of claims on food labels. In turn, the dominance of such claim 'information' on the food label potentially may sway consumers' food decision making ${ }^{(15,16)}$ and undermine other health education initiatives.

\section{Methods}

A mixed-methods approach used two previously validated quantitative questionnaire instruments that provided measures of the level of control the officers exercised over their work, as well as qualitative semistructured, in-depth interviews. Ganster's Job Control Scale ${ }^{(22)}$ and Karasek's Job Decision Latitude Scale ${ }^{(23)}$ provided data to complement participants' responses to the interview questions. The work and control scales survey data were analysed using the statistical software package SPSS version 15 for Windows.

Following completion of the quantitative questionnaires, semi-structured interviews were conducted with environmental health officers. The interviews were audio-recorded and transcribed for analysis. The transcripts were analysed by coding for topics and themes ${ }^{(24)}$ using the software QSR NVivo 7.

A non-probability purposive sample was selected to capture a sample most likely to bring to light the work practices reported to be of interest. Criteria included varied work structures, professional experience and seniority, and different levels of governments ${ }^{(17-19)}$. Environmental health officers were sought in three jurisdictions in Australia (New South Wales (NSW), Australian Capital Territory (ACT) and Queensland (QLD)) to provide a range of work structures. Sixty-eight responses were received from local councils and state authorities. Of these, fifty-five local councils from NSW and QLD granted approval for the study, and thirteen said no. The reasons stated for not granting approval included "we currently have no environmental health officers on staff', 'currently have not trained staff' and 'do not wish to participate at this time'.

The number of participants interviewed was determined by two constraining factors: time and anticipated data saturation $^{(24,25)}$. Interviews were scheduled as potential participants responded, while ensuring a cross-section of inclusion criteria was met. Interviews proceeded until data saturation was achieved; that is, when no new themes and ideas were being reported ${ }^{(24)}$. A total of thirty-nine environmental health officers participated. Data from two officers were incomplete due to technical and scheduling problems.

The study was conducted according to the guidelines laid down in the Declaration of Helsinki and all procedures involving human subjects were approved by University of Wollongong's Human Research Ethics Committee (HE06/010). Written informed consent was obtained from all participants.

\section{Results}

Thirty-seven participants with a full cross-section of professional characteristics completed both questionnaires and interviews (Table 1). Quotes from officers' interviews have been identified by an ID number; their position at 
Table 1 Characteristics of Australian environmental health officers ( $n$ 37) who completed both interviews and questionnaires

\begin{tabular}{lr}
\hline Category & $n$ \\
\hline Sex & \\
Males & 23 \\
Females & 14 \\
Seniority & \\
$\quad$ Junior officer & 22 \\
$\quad$ Senior officer & 15 \\
Location & \\
$\quad$ Urban & 15 \\
$\quad$ Rural & 22 \\
Government level & 28 \\
$\quad$ Local government & 9 \\
State government & \\
State & 4 \\
Australian Capital Territory & 21 \\
New South Wales & 12 \\
Queensland & \\
\hline
\end{tabular}

state or local level; whether they were a senior or field (junior) officer; and the line number/s of the transcribed interview.

\section{Environmental bealth officers' responsibilities and workload}

Environmental health officers reported a sizeable workload. Their role included three main areas of activity: food safety, protection of environmental and public health, and education. Within these three areas there was a broad range of activities that differed according to jurisdiction, locality or seniority. Duties in relation to food were focused on food safety or hygiene, complaints originating from the public or industry, audits of food premises and food recalls when necessary.

State-level and senior officers reported that they advised the government on food safety issues by preparing ministerial briefs as requested. They also reported liaising with elected members of council, talking to industry or schools regarding food safety and handling or environmental issues, and managing local government projects in the community. In addition, state and senior officers liaised with other government organizations and reported more involvement with management, interaction with outside organizations and political sensitivities:

'...for state government it's more [the] consequences of what the media will do if we [the government department] don't respond.' (EHOS39, state, field, line 364)

The senior officer's duties were reported as more organizationally focused:

'...the focus is on key result areas, targets, always in the background, like that high-risk issue is for the benefit of all, but as far as my day-to-day planning ... to achieve the organizational goals would be the first priority...' (EHOS38, senior, lines 358-363)
Local officers reported a more community-oriented role. They worked proactively through their routine inspections of premises posing a risk to the community's health, enforcing compliance with regulations and codes, and by educating food handlers in proper hygiene. They also worked reactively to investigate complaints arising from the community, for example possible food contamination or poisoning. Decisions regarding the priority of daily activities were based on a mixture of risk assessment, complaints from the public, crisis management and enforcement of regulations. The magnitude and value of the duties can be illustrated by the following excerpt:

'Huge, definitely huge. They are the first contact between the community and public health; their role is very important in providing advice to the community in relation to food safety, ... and they've got a very, very difficult job and tasks to perform in a single day.' (EHOS34, senior, lines 124-133)

Local officers, due to their proximity to the community, were a 'first stop' for community enquiries, concerns and complaints, with most time taken with 'complaint investigation' and 'routine inspections'. Complaints about food premises or food handling were regarded as serious and received priority.

\section{Autonomy and work control}

Environmental health officers at all levels reported a high level of autonomy in their work practices, rarely being given direction by a supervisor:

'...our manager [says] we're professionals, we can organize our own time ... it's up to us to meet the deadlines that we've been given.' (EHOS11, local, field, lines 128-133)

Senior officers' reports confirmed such autonomy, although they also exerted some influence over daily priorities in the field:

'I don't interfere with how the staff manage their work, but I may alert them to something that needs to be done sooner rather than later.' (EHOS36, state, senior, lines 381-384)

The high degree of autonomy reported in the interviews was very consistent with the results obtained from the two survey instruments. Officers reported exercising a high degree of control over their work practices, consistent with the high mean score above 3.6 obtained for overall work control measures using the Ganster work control scale. Table 2 provides mean response scores for a subset of survey questions, to illustrate the degree of work control. The overall mean of 3.6 indicates that the officers had freedom to plan their activities and they were required to make daily decisions to prioritize their heavy workload. 
Table 2 Response scores for a subset of survey questions on Ganster's Job Control Scale ${ }^{(22)}$ among Australian environmental health officers $(n 37)$

\begin{tabular}{|c|c|c|c|c|c|}
\hline Item & $n$ & Min & Max & Mean & SD \\
\hline Control over amount of work completed & 38 & 2 & 5 & $3 \cdot 68$ & 0.96 \\
\hline Control over speed of work & 38 & 2 & 5 & $3 \cdot 71$ & $0 \cdot 87$ \\
\hline Control over scheduling and duration of breaks & 38 & 1 & 5 & $3 \cdot 82$ & $1 \cdot 09$ \\
\hline Control over how work is done & 38 & 2 & 5 & $4 \cdot 05$ & $0 \cdot 77$ \\
\hline General control over work and work related matters & 37 & 1 & 5 & $3 \cdot 68$ & $0 \cdot 78$ \\
\hline
\end{tabular}

Table 3 Response scores for the Decision Authority component of Karasek's Job Decision Latitude Scale survey ${ }^{(23)}$ among Australian environmental health officers ( $n$ 37)

\begin{tabular}{|c|c|c|c|c|c|}
\hline Item & $n$ & Min & Max & Mean & SD \\
\hline Make decisions on my own & 38 & 1 & 5 & $4 \cdot 11$ & $1 \cdot 00$ \\
\hline Have very little freedom to decide how I work & 38 & 1 & 5 & $2 \cdot 13$ & 0.91 \\
\hline Have a lot of say about what happens on my job & 37 & 1 & 5 & $3 \cdot 70$ & 0.94 \\
\hline
\end{tabular}

Table 3 presents results from the Decision Authority component of Karasek's Job Decision Latitude Scale survey. A mean score of $4 \cdot 11$ for question 1 of the decision latitude items indicates a high degree of autonomy in decision making and the low mean score of $2 \cdot 13$ for the reverse question, 'I have very little freedom to decide how I work', further supports health officers' degree of autonomy. These results are indicative only, as the sample size is small and only questions from the Decision Authority component of the Job Decision Latitude Scale were asked.

\section{Environmental bealth officers: prioritizing the tasks}

All officers, regardless of position, reported that the most important factor influencing their work practice was the assessment of risk to public health and they would respond first to incidents posing the highest danger. Officers reported that within the legal guidelines they were often required to use discretion and to prioritize activities according to the risk:

'The assessment of risk of, if we didn't do it, .... which would have the greatest negative consequence? ... food shops.' (EHOS27, local, field, lines 192-197)

Legislation required the regular inspection of food and other premises but individuals reported applying their discretion to risk analysis to set the frequency of their inspections. Locations with high-risk or vulnerable populations, such as nursing homes or child-care centres, or high-risk premises (e.g. those handling seafood or raw chicken), were inspected more frequently than premises deemed lower risk.

Environmental health officers reported a belief that their role was to protect the community's health. Local officers rated complaints according to their assessment of the danger posed to the public. Events posing an immediate threat to public health were given highest priority, such as modifiable disease outbreaks and foreign matter or bacteria identified in food necessitating investigation and possibly food recall.

In addition, internal organizational expectations influenced officers' prioritization of their work, creating tensions. For example, management and budget considerations affected work practice, so that the government policy for 'cost recovery' of (audit and other) services may have resulted in skewing of work activities to generate funds to provide the service, as reflected in the following quote:

'... but one of the things they have to face on a daily basis is prioritizing their work ... if they don't do enough audits then we go broke and you don't have a job ... balanced against ... all these complaints that the consumer's ringing up and saying why haven't you done my complaint?' (EHOS36, state, senior, lines 272-283)

Another departure from the principal theme of risk analysis was the influence on senior officers of external pressures, such as the media or from elected officials:

'Yes, [risk analysis] comes into it a lot, but for state government it's more [the] consequences of what the media will do if we don't respond rather than what health effects it will have ... or ministerial requests. Things like that get priority.' (EHOS39, state, field, lines 363-368)

Nearly half of local officers interviewed also expressed concern about the state government's capacity for 'passing on' responsibilities to local government, adding to their workload, without providing support and resources. Local officers felt that their ability to take on duties that did not fit anywhere else, and their adaptability 
and willingness to take responsibility for 'extras' made it easier for the state or other local government departments to shift work to them. 'Jack of all trades' was used to describe this ability to adapt and find ways to get things done.

A further difficulty identified was the complexity and amount of legislation. Officers described the difficulties they faced in trying to maintain a working knowledge of a large amount of legislation and applying it in different situations. Reported problems included: 'ambiguous wording'; 'open to interpretation'; 'too complex'; and 'makes it difficult to take immediate action when necessary'.

\section{Health claims labelling and the role of environmental bealth officers}

Officers were asked to consider the implications for their work of the monitoring of the veracity of health-related claims. Local officers predominantly stated that their role in the area of inspecting food labelling was limited to checking minimum weight, use-by dates and observing quality of food products (i.e. visual appearance related to soundness of the product). About one-third of local officers reported that monitoring of claims on food labels was the responsibility of the state agencies and that the monitoring of a nutrition, health and related claims standard would be a state-level responsibility. State officers reported that while inspection of claims on food labels was under their jurisdiction, it was done in response to complaints rather than as a routine practice.

Local-level officers expressed concern that this monitoring role would be passed down to the local level:

'...State seems to love legislating for these things ... local government often ends up having to try and administer it ... it gets pushed down to our level...' (EHOS17, local, senior, lines 709-714)

Five (of twenty-eight) local government officers stated that they were responsible for limited monitoring of claims but were uncomfortable with their ability in this area:

'...that's one area where I really think my skills aren't $100 \%$ up to scratch...' (EHOS03, local, senior, lines 294-297)

Local officers expressed further concerns about guidance and their capacity to interpret and implement that guidance. The language used in standards, policies and legislation was reported by officers as not always being clear, leaving the officers unsure of the intent. In addition, the training available to officers in how to interpret and implement policy was often insufficient. Local officers reported concern about understanding the difference between different types of claims:

'... if it's going to be advantageous to cardiovascular improvement or anything like that, that goes back to the professionals who know that. I'm not a doctor...' (EHOS29, local, senior, lines 474-480)

Local officers also believed the state did not have sufficient resources to undertake monitoring and assessment of health and related claims at the state level. In addition, officers reported that they would prioritize food safety ahead of health claims:

'... if there's adequate officers to look at that specific issue [health claims] then yes I think it will be taken seriously, and will be a fairly high priority ... if it's left to existing staff, ... and looking at a label claiming fat free, I just don't think that the risk posed by that particular issue is going to take precedence.' (EHOS24, local, field, lines 546-555)

The response also reflects officers' belief that health claims were not a public or environmental health risk, but rather a marketing or fair trading issue, positioning them as primarily marketing tools.

When asked to place monitoring health and related claims on a scale of $1-10$, with 1 being the lowest priority and 10 being the highest, local government officers placed monitoring health claims below the most highly prioritized matters of public health risk, such as poor food handling and food-borne illness outbreaks. In particular, health-related claims and labelling did not appear consistent with the notion of 'altruism', which appeared as a common thread in the description given by both state and local government officers regarding their duties. For example, officers described their actions was 'protecting consumers' health' and 'reassuring the public that the food they purchased or ate [in a café] was safe and was not going to make them sick'. Other phrases such as 'watchdog' of well-being and 'protector of community health and well-being' also illustrate the perceived altruistic character of officers' roles. Monitoring of healthrelated claims was not portrayed in this manner.

\section{Environmental health officers as street-level bureaucrats: applying Lipsky's model}

Results from the interviews and questionnaires indicated that the environmental health officers who participated in the study had a very high and diverse workload, and exercised considerable autonomy and control over this through the priorities they gave to specific tasks on a daily basis. However, they were subject to the constraints of different priorities of management, budget, media and politics, and the complexity of legislation in the area. Results indicated that local officers considered themselves to be protectors of the community's health, closely interacting with the community and responding to its demands and complaints. Their routine inspections and investigation of food poisoning and hygiene complaints were given highest priority, while monitoring food label claims was given low priority. Conversely, senior 
Table 4 Consistencies of Australian environmental health officers' interview and questionnaire data with Lipsky's theory ${ }^{(20)}$

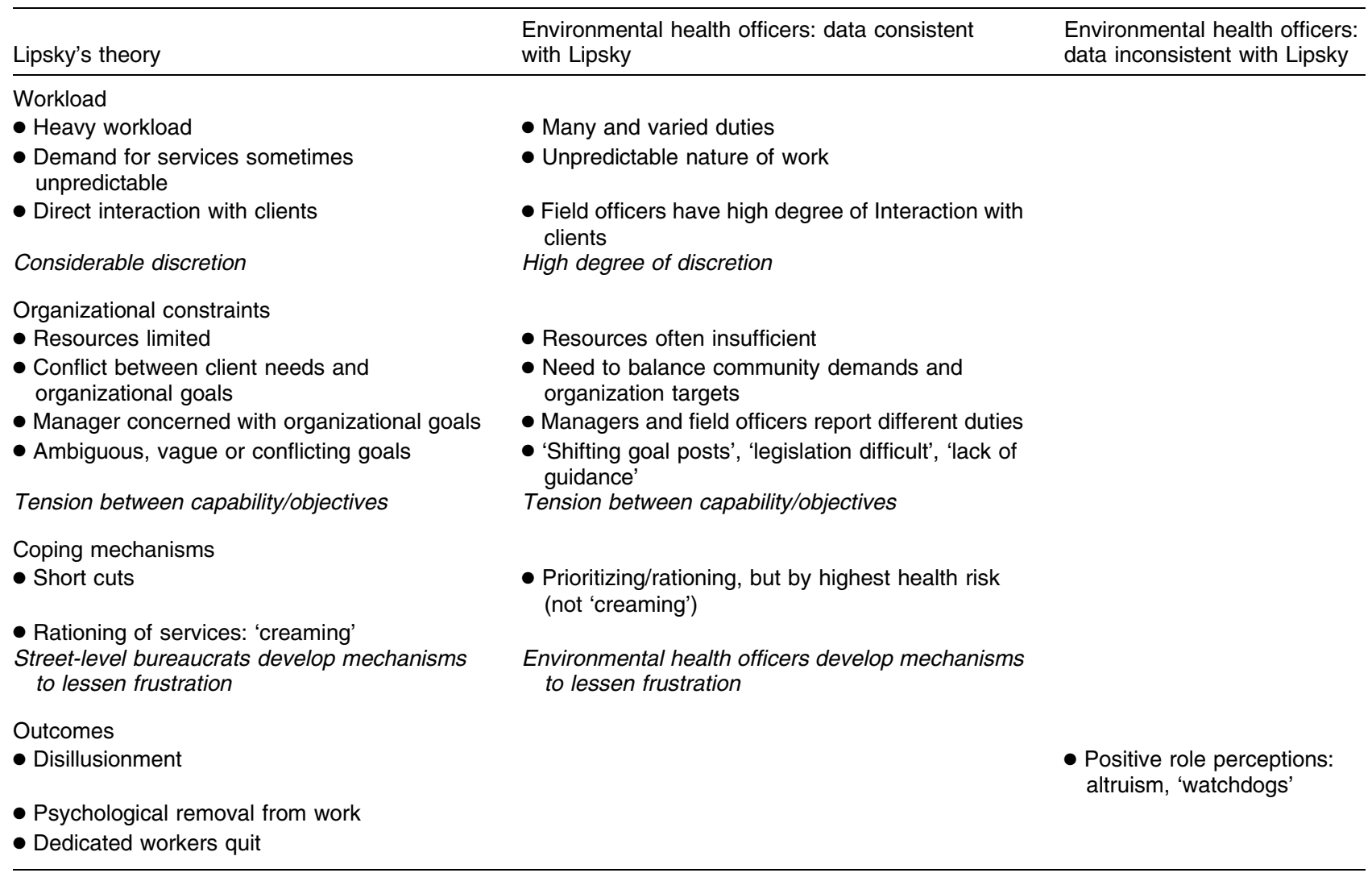

officers reported being more involved with management, interacting with outside organizations and politics, and assigned higher priority to the monitoring of health claims on food labels.

Analysis indicated there were many consistencies between these results and Lipsky's theory, as illustrated in Table 4. These consistencies broadly included workload and client demands; organizational constraints, including complex and imprecise legislation, shifting goal posts and lack of guidance, the struggle to enforce imprecise policy with insufficient resources; and the officer's use of coping mechanisms to manage his/her workload, given the constraints of the workplace.

\section{Discussion}

Results from the present study indicate that environmental health officers, through their work practices and especially in their enforcement role, have the capacity to affect the implementation of policy at the community level and to optimize or lessen the benefits to consumers of policy and food regulations, such as nutrition and health related claims on food labels.

Environmental health officers reported that they operate in a manner similar to that described by Lipsky's street-level bureaucrats. They used their professional expertise to address the needs of their clients; enforced sometimes vague policy which was open to interpretation; and exercised a high degree of discretion in decision making. The field officers' responses regarding complexity and imprecise legislation, shifting goal posts and lack of guidance confirmed that, as described by Lipsky, environmental health officers struggled to enforce imprecise policy with insufficient resources.

The officers' discourse reflected a strong sense that they regarded themselves as 'watchdogs' over the community's public health, also consistent with Lipsky's description of the people attracted to public service as idealistic and dedicated to their helping profession. Such traits, said Lipsky, often led to disillusionment when faced with the reality of not being able to make improvements in the lives of their clients. Consequently, Lipsky $^{(20)}$ (p. 143) argued, workers who were the most dedicated quit, or they may psychologically remove themselves from the work.

Field officers' responses indicated that within their work practice they were given minimal guidance but were expected to exercise discretion in performing their routine public health and environmentally relevant activities. Lipsky argued that a lack of clarity of goals, and insufficient resources to meet all goals, resulted in short cuts being implemented by street-level bureaucrats to cope with the demands on them. In reports on the work 
of nurses ${ }^{(26)}$, and in the area of social work ${ }^{(27)}$, policy was not fully implemented due to workers' inability to cope with increasing demands being placed on them. Earlier studies have shown similar findings ${ }^{(28,29)}$. This potentially is a risk for the implementation of changes in food labelling policy.

The present study found that environmental health officers were managing to meet current operational guidelines without short cuts, despite an acknowledgement by some officers of a lack of guidance. Results suggested that environmental health field officers, by prioritizing the jobs (complaints) by degree of risk to environmental or public health, were 'rationing' benefits to best protect public health, a positive outcome. Such 'rationing' of services had a focus on maximizing benefit to the community, differing from Lipsky's 'rationing' of services, which focused on decreasing personal frustration in response to work overload. Similarly, previous studies suggest that the work practices of street-level bureaucrats in comparable 'helping' professions (therapists, social workers, school psychologists) were focused on the client, using operational policy to fit clients' needs, rather than compromising clients' needs to fit policy $^{(28-31)}$. The method of prioritizing reported by environmental health officers was employed because the officers believed it most effective in ensuring protection of the community's health.

Rationing of services as a coping technique to manage the constraints and minimize the frustrations experienced in the workplace was not reported in the present study. Rationing, said Lipsky, was used to decrease the frustration people experienced when trying to meet excessive demands from their organization and the public. One such rationing strategy was choosing to do those jobs that had greater potential to have a positive outcome over the more difficult ones ('creaming') (20) (p. 107). These 'rationing' techniques carry a negative connotation as they ultimately may decrease the benefits to the community. Contrary to this perspective, the environmental health officers' responses depicted a motivation to increase job satisfaction and a 'desire and wish to provide public service', ultimately to benefit their community.

The findings of the present study also indicated that new policy initiatives such as nutrition, health and related claims were not well understood by the responsible professionals, lacked intuitive alignment with how they judged risks to public health, and were not seen as a management or community priority. Consequently the policy was not likely to receive well-considered attention within the autonomous work environment described by these environmental health officers. The officers reported they would give monitoring such a new policy a lower priority than their food safety responsibilities. They did not believe that it was really their role to undertake such monitoring and if they did, that they were ill equipped to do so.
Development of healthy public policies needs to consider the implementation and monitoring of such policy, including the influence and actions of responsible officers, if it is to be effective in achieving the desired outcomes of reducing consumers' concerns regarding being 'duped' by manufacturers' claims ${ }^{(8)}$ (p. 13) and maintaining consumers' trust in information on the food label $^{(32)}$. In addition, clear delineation of roles could be considered between responsible agencies, such as has occurred in the state of NSW(33).

A limitation of the study was inclusion of environmental health officers from only three jurisdictions. Each State and Territory in Australia has different structures through which it undertakes its responsibility for monitoring and enforcement of the food standards. These structures provide varying support for and place different expectations on environmental health officers and how they undertake their roles. Thus the results of the present study may not fully reflect the perspectives of environmental health officers across Australia. If a larger, more representative study were to be undertaken, use of the full Decision Authority component of the Job Decision Latitude Scale $^{(23)}$ and Job Control Scale ${ }^{(22)}$ would provide more substantive measurement and allow the results to be compared with other studies.

\section{Conclusion}

New policy directives are not automatically adopted by professionals who are already juggling multiple responsibilities and do not consider them as high priorities. The potential to support nutrition messages via on-label nutrition, health and related claims will not be met if officers responsible to monitor the use of such claims do not see the importance of or are not enabled to undertake this role.

The results of the present study have extended Lipsky's model into a new area of work practice. Contrary to previous studies indicating that street-level bureaucrats use coping mechanisms to decrease frustration caused by work conditions, the desire to create positive outcomes for the community drove the behaviour of environmental health officers.

Three major recommendations arise out of our study. There should be provision of sufficient resources and timely training in new responsibilities for environmental health officers. Communication between State and local government authorities must continue to be improved and maintained, for example through memoranda of understanding or more detailed legislation of enforcement roles, so that adequate support and appropriate guidance from team leaders are consistently available. Lastly, increased consumer education regarding the importance of nutrition, health and related claims as a tool to make healthier food purchases is needed, to 
reinforce with officers the importance of their role in monitoring such claims.

\section{Acknowledgements}

Sources of funding: This research received no specific grant from any funding agency in the public, commercial or not-for-profit sector. Conflicts of interest: No author had a personal or financial conflict of interest. Authors' contributions: D.C.-P. conceptualized and wrote the manuscript and conducted and reviewed the analyses, especially the qualitative analyses. H.R.Y. reviewed and revised the manuscript, oversaw the study design and conducted and reviewed the analyses. E.G.-D. developed the study design in collaboration with H.R.Y. and collected and analysed the data in collaboration with D.C.-P. and H.R.Y., as part of the research for a thesis for an MSc (Research) degree.

\section{References}

1. Tee ES (2000) Labelling, nutrition and health claims: what's happening in Southeast Asia. Food Aust 52, 249-251.

2. Cheftel J (2005) Food and nutrition labelling in the European Union. Food Chem 93, 531-550.

3. Australia New Zealand Food Regulation Ministerial Council (2003) Policy Guideline on Nutrition, Health and Related Claims. Canberra: Australian Government.

4. Williams P, Yeatman H, Zakrzewski S et al. (2003) Nutrition and related claims used on packaged Australian foods implications for regulation. Asia Pac J Clin Nutr 12, 138-150.

5. Food Standards Australia New Zealand (2013) Standard 1.2.7 Nutrition, Health and Related Claims. Canberra: Australian Government ComLaw.

6. Worsley A (1996) Which nutrition information do shoppers want on food labels? Asia Pac J Clin Nutr 5, 70-78.

7. McCaughey W, Australia New Zealand Food Authority \& Yann Campbell Hoare Wheeler Research (1996) National Consumer Survey of Food Labelling. Canberra: Australian Government Publishing Service.

8. Paterson D, Zapelli R \& Chalmers A (2001) Food Labelling Issues - Consumer Qualitative Research. Canberra: Australia New Zealand Food Authority.

9. Food Standards Australia New Zealand (2005) Food Labelling Issues: Qualitative Research on Participants' Perceptions and Use of Nutrition, Health and Related Claims on Packaged Foods and Associated Advertising Material. Canberra: FSANZ.

10. Food Standards Australia and New Zealand (2007) Food Standards Code. Canberra: FSANZ.

11. Gorton D, Mhurchu CN, Chen MH et al. (2009) Nutrition labels: a survey of use, understanding and preferences among ethnically diverse shoppers in New Zealand. Public Health Nutr 12, 1359-1365.

12. Harris JL, Thompson JM, Schwartz MB et al. (2011) Nutrition-related claims on children's cereals: what do they mean to parents and do they influence willingness to buy? Public Health Nutr 14, 2207-2212.

13. Grunert KG, Wills JM \& Fernandez-Celemin L (2010) Nutrition knowledge, and use and understanding of nutrition information on food labels among consumers in the UK. Appetite 55, 177-190.

14. Hughes C, Wellard L, Lin J et al. (2013) Regulating health claims on food labels using nutrient profiling: what will the proposed standard mean in the Australian supermarket? Public Health Nutr (Epublication ahead of print version).

15. Gorton D, Mhurchu CN, Bramley D et al. (2010) Interpretation of two nutrition content claims: a New Zealand survey. Aust N Z J Public Health 34, 57-62.

16. Chan C, Patch C \& Williams P (2005) Australian consumers are sceptical about but influenced by claims about fat on food labels. Eur J Clin Nutr 59, 148-151.

17. Environmental Health Committee (2009) enHealth Environmental Health Officer Skills and Knowledge Matrix. Canberra: Australian Government Publishing Service.

18. Pham MD, Jones AQ, Sargeant JM et al. (2010) A qualitative exploration of the perceptions and information needs of public health inspectors responsible for food safety. BMC Public Health 10, 345-353.

19. Windsor \& Associates (2005). Environmental Health Officer Workforce Review. Report Prepared for the Food Safety Unit, Department of Human Services. Canberra: Australian Government Publishing Service.

20. Lipsky M (1980) Street-Level Bureaucracy: Dilemmas of the Individual in Public Services. New York: Russell Sage Foundation.

21. Vinzant J \& Crothers L (1996) Street-level-leadership: rethinking the role of public servants in contemporary governance. Am Rev Public Admin 26, 456-481.

22. Dwyer DJ \& Ganster DC (1991) The effects of job demands and control on employee attendance and satisfaction. J Organ Behav 12, 595-608.

23. Karasek R, Brisson C, Kawakami N et al. (1998) The Job Content Questionnaire (JCQ): an instrument for internationally comparative assessments of psychosocial job characteristics. J Occup Health Psychol 3, 322-355.

24. Patton MQ (2002) Qualitative Research and Evaluation Methods, 3rd ed. Thousand Oaks, CA: Sage Publications.

25. Strauss A \& Corbin J (1998) Basics of Qualitative Research: Techniques and Procedures for Developing Grounded Theory. Thousand Oaks, CA: Sage Publications.

26. Bergen A \& While A (2005) 'Implementation deficit' and 'street-level bureaucracy': policy, practice and change in the development of community nursing issues. Health Soc Care Community 13, 1-10.

27. Meyers MK, Glaser B \& Mac Donald K (1998) On the front lines of welfare delivery: are workers implementing policy reforms? J Policy Anal Manage 17, 1-22.

28. Summers AP \& Semrud-Clikeman M (2000) Implementation of the IDEA by school psychologists: an exploratory study using the theory of street-level bureaucracy. Sch Psychol Q 15, 255-278.

29. Maynard-Moody S \& Musheno M (2000) State agent or citizen agent: two narratives of discretion. J Public Admin Res Theory 10, 329-358.

30. Riccucci NM (2005) Street-level bureaucrats and intrastate variation in the implementation of temporary assistance for needy families policies. J Public Admin Res Theory 15, 89-111.

31. Nielsen VI (2006) Are street-level bureaucrats compelled or enticed to cope? Public Admin 84, 861-889.

32. Taylor AW, Coveney J, Ward PR et al. (2012) The Australian Food and Trust Survey: demographic indicators associated with food safety and quality concerns. Food Control 25, 476-483.

33. NSW Government (2010) Food Regulation 2010 Under the Food Act 2003, N. Parliament. Sydney: NSW Government. 